\title{
Factor Masculino en la Infecundidad
}

\author{
Doctor Alfonso Ramírez C. \\ Urólogo de Unidia. Urólogo del Hospital de San José. \\ Miembro de The International Fertility Asociation.
}

La importancia del factor masculino en los casos de esterilidad matrimonial, ha verido a ozupar el puesto que realmente le corresponde en el estudio de la pareja estéril, ya que según estudios estadísticos recientes en medios como Norte América, han demostrado que del 10 al 15\% de los matrimonios están impedidos para tener hijos y en estos matrimonios el varón constituye o es el único factor causal de un 30 a un $50 \%$.

\section{Etiopatogenia:}

Causas endocrinas de orden hipofisiario por insuficiencia como sucede en el síndrome de Frohlich, infantilismo pituitario de Levi-Lorain y el síndrome adiposo-genital en los cuales existen trastornos de la espermatogénesis; de orden tiroideo $\mathrm{y}$ las intrínsecamente testiculares. Enfermedades metabólicas como la diabetes, carenciales con hiponutrición y avitaminosis. Enfermedades infecciosas de proceso febril alto como ha sido demostrado por los estudios de John MacLeod de la Universidad de Cornell en enfermos atacados de varicela v neumonía. Con la primera entidad un paciente mostró descenso del número de espermatozoides de 315 millones por c. c. a 3 millones por c. c. con una morfología anormal de un $62 \%$ y una movilidad escasa de un $10 \%$. En la segunda entidad, la neumonía, un paciente mostró descenso en el espermograma de 126 millones hasta llegar a la total azoospermia después de 55 días de haberse iniciado la enfermedad. Con mucha mayor razón buena parte de las enfermedades febriles de la niñez deben afectar el epitelio germinal del testículo cuando está en periodo de desarrollo o maduración de la pubertad que afectan muchas veces en forma definitiva los tubos seminíferos y son causa de la infecundidad del adulto. Otras causas mejor definidas y estudiadas son el criptorquidismo bilateral, las orquitis urlianas antes o después de la pubertad, las atrofias del epi- 
telio germinal debido a las irradiaciones nocivas, especialmente de Rayos X, las atrofias testiculares por trauma quirúrgico en las intervenciones del cordón espermático o hernias, causas inflamatorios del epididimo y canal deferente debido especialmente a la blenorragia, T.B.C., gripales, de virus, etc., que causan oclusión bilateral; las ausencias congénitas de los canales deferentes o de los epididimos.

De los órganos accesorios pudiéramos llamar, aquellas entidades responsa bles de la infecundidad, que encontramos en la próstata, vesículas seminales, canales evaculadores, veru-montanum, papilomas del mismo, estrecheces uretrales, uretritis, estrecheces congénitas del meato, hepispadias e hipospadias que impiden el propio depósito del semen en la cavidad raginal y aquellas que afectan el liquido seminal con detritus, mucus o pus y provocan condiciones adversas para la fecundación. De esto se desprende el que sea imperioso un estudio urológico completo para descartar dichas entidades, valorarlas justamente de acuerdo con jos otros hallazgos. Una historia clínica juiciosa con datos relativos a frecuencia del coito, función sexual, potencia, evaculación, orgasmo y estudio clínico completo contribuven y son necesarios para un dignóstico correcto. De fundamental importancia en la esterilidad masculina se destaca: a El estudio del espermograma; $b$ La biopsia testicular; c Las manifestaciones clinicas de orden hipofisiario, tiroideo o testicular y de los órganos accesorios; e Dosificación de gonadotropinas y 17 cetoesteroides.

\section{ESPERMOGRAMA Y SU INTERPRETACIÓN:}

Para la realización del espermograma, la forma de recolección es importante: se acepta hoy como el mejor procedimiento la evaculacion en recipiente de vidrio, seco y estéril. La recolección por coito interrumpido es impropia y puede ocasionar un error grande, ya que está demostrado que en las primeras gotas de la evaculación, se elimina hasta un $75 \%$ del numero de esprematozoides. Además, la facilidad de contaminación al recoger la muestra puede ocasionar trastornos en la vitalidad y movilidad espermatica. Lo mismo o algo similar ocurre con el uso de preservativos por la posibilidad de alteracion celular. Para un espermograma adecuado, según Edmond Farris "un minimum de cinco días de abstinencia son necesarios para alcanzar el nivel maximo de fertilidad; emisiones diarias o interdiarias reducen el número de espermatozoides hasta un nivel de sub-fertilidad". Algunas veces y para valorar posibles datos de error, conviene el estudio de dos o tres espermogramas. El estudio del semen debe iniciarse una o dos horas después de la recolección, tiempo en el cual la licuefacción debe ser completa y además por el hecho de disminuír rápidamente la movilidad de los espermatozoides.

Las caracteristicas normales más importantes que deben estudiarse en el espermograma son: el número de espermatozoides, el volumen evaculado, opacidad, viscosidad, motilidad, vitalidad y formas y elementos anormales. 
Los caracteres físicos del semen fresco como su consistencia gelatinosa, cohesión, opacidez o translucidez, deben estudiarse macroscópicamente y pueden dar idea de algunas de las entidades o anormalidades: en las azoospermias por obstrucción epididimaria el flúido seminal tiene más o menos las mismas características que el normal, pero es más traslúcido. Esto contrasta con el exceso de fluidificasión, pérdida de consistencia que puede observarse en las enfermedades de las glándulas accesorias en donde además se encuentran detritus, piocitos y mucus.

\section{VOLUMEN :}

El volumen varia aún en el mismo individuo desde 1,5 c.c. hasta 6 c.c. y estas variaciones se observan tanto en el hombre fértil como en el estéril. Estas variaciones de volumen no tienen mayor significación, salvo en aquellos casos en que se encuentre por debajo de 1,5 c.c. o por encima de 7 c.c.; este aumento de volumen generalmente coexiste con un semen de muy pobre calidad, formas anormales y oligospermia.

\section{Número de espermatozoides:}

No se puede establecer un número fijo por encima del cual se hable de extrema o gran fertilidad. ni tampoco por debajo del cual se pueda hablar de un individuo irreparable esteril. Se han hecho clasificaciones como las de Farris quien considera de gran fertilidad cifras que están por encima de 185 millones en el total del volumen evaculado; de relativa fertilidad entre 80 y 185 millones $y$ sub-fértil de 1 a 80 millones. No obstante aunque el número de espermatozoides sea escaso es muy probable que hava fecundación si las demás caracteristicas hablan en favor de una magnífica calidad de semen, especialmente la movilidad, vitalidad y escasas formas anormales. Aquí sí cabe decir que no se puede reemplazar "calidad por cantidad". Es por esta misma razón que las fórmulas que se han hecho con distintos factores, como son el volumen, concentración espermatica, morilidad y morfología, con el fin de allegar el factor Indice de Fertilidad. no son precisas. Como lo dice Walter W. Williams: "Una eculacion matemática no es apta para aumentar las probabilidades de tener un baby". Cosa muy distinta si al factor de hipoespermatogénesis, se suman otras alteraciones y eso es generalmente lo que sucede.

\section{Motilidad:}

Es el elemento de más valor en el espermograma. Una buena movilidad está en favor de buena vitalidad y existe una estrecha relación de la movilidad con la longevidad del espermatozoide. Muestras que ofrecen buena movilidad inicial, según varios autores, viven largo tiempo y viceversa en aquellas muestras de escasa movilidad, la mayor parte de los espermatozoides están muertos antes 
de las 24 horas. En el estudio de la motilidad debe tenerse en cuenta el movi miento de progresión para su evaluación. En el sujeto normal se admiten de 60 a $70 \%$ de formas móviles cuando se examina la muestra a la media hora des pués de la recolección y tenga una fluidificación adecuada.

\section{Morfología y vitalidad:}

Se admiten hasta un $20 \%$ de formas anormales, con anomalías de cabeza cuello y cola; por encima de este porcentaje es poco probable la fecundación Según Farris, las muestras que se consideran de gran fertilidad pueden perma necer como tales in vitro por espacio de 19 horas, mientras que muestras de re lativa fertilidad sólo permanecen 9 horas. En el cuello uterino, utero y trompa: se han encontrado células normales móviles hasta 48 horas después de la inse minación y es posible que hayan podido vivir mayor tiempo; no obstante e mismo autor concluye que el poder fecundante se pierde después de 24 horas va que cuando la inseminación se practicó antes o después de las 24 horas de tiempo de ovulación, no hubo fecundación.

Henry C. Falk y Sherwin A. Kaufman del Beth Israel Hospital, en la ciu dad de Nueva York, realizaron un estudio en 100 hombres de comprobada fer tilidad, con sus mujeres embarazadas cuando se realizó el estudio, con dos o más hijos y sin antecedentes de abortos. De dicho estudio concluven: $61,4 \%$ con células activas después de 3 horas; $46,5 \%$ con células activas después de 6 horas y $26,5 \%$ con células después de 12 horas. Nueve individuos mostraron escasa movilidad celular espermática. Se encontraron menos de 60 millones de esper matozoides en un $15 \%$ y menos de 40 millones en un $7 \%$. El promedio pare todos fue de 100 millones. Formas anormales de un 3 a un $30 \%$. Formas nor males $88,4 \%$. El promedio de formas anormales fue de $11,6 \%$.

\section{Biópsia TESTICULAR:}

La importancia de la biopsia testicular es innegable en los últimos tiempos Por ella se pone de manifiesto: $1^{\circ}$ Aquellos casos que son susceptibles de tra tamiento. $2^{\circ}$ Aquellos pacientes irrevocablemente estériles a la luz de los trata mientos actuales. 30 Pacientes para los cuales existen muy pocas probabilidade de tratamiento, y $4^{\circ}$ El resultado y eficacia de los tratamientos instituídos cor biópsias hechas antes y después.

Clínicamente por el examen somatico testicular y epididimario, consistenci: y tamaño de los testículos $y$ antecedentes se puede sospechar que la causa d una azoospermia se debe a obstrucción del epididimo o canal deferente o a un: aplasia o hipoplasia germinal: se puede sospechar digo, pero no se puede tener l: certeza; es en este caso concreto que la biopsia viene a dar la respuesta definitiva

La biópsia testicular propiamente ejecutada además de ser de ejecución sen cilla, es segura, atraumatica e inocua para el paciente. Ahorra tiempo y quizá tra tamientos de costo alto para el enfermo que al final de cuentas muchas vece no han de beneficiarlo. 


\section{Técnica: Anestesia: Técnica de Simons:}

Para las estrecheces o fibrosis del canal en cierta extensión: ver técnica descrita por Lewis Michelson con guía o alma de acero.

\section{TFATAMiento:}

En los fenómenos obstructivos la epididimo-vasostomía: Técnicas de Hagner. La modificación de Bayle usando la hebra de tantalium. Técnica de Lewis Michelson preconizada en 1945. La primera epididimo-vasostomía con éxito se remonta a 1902 reportada por Martin. Porcentaje: va desde 65\%. Reed Nesbit v Retchkiss 13 a $25 \%$.

En los trastornos por hipofunción hipofisiaria el uso de Gonadotropinas. Así mismo en los hipotiroideos el uso de tiroides comenzando con dosis pequeñas de 0,032 grs. hasta llegar a 0,32 grs.

Recientemente el uso del propionato de testosterona (trabajos de Norris J. Heckel, W. A. Rosso y Lucile Kestel, de Chicago). Hasta producir la azoospermia (dosis total 2.500 miligramos), dosis de 150 miligramos semanales, parece que da buenos resultados. Este fenómeno se explica por una depresión hipofisiaria y una inhibición secundaria de la espermatogénesis. Esta supresión causa posteriormente un estímulo y se observa "el rebound fenómeno" que es una espermatogénesis gradual progresiva superior en varios millones a la anterior. Fluctúa de 22 millones hasta 79 millones. En el último congreso y primero mundial de esterilidad se comentó que esta medicación no está exenta de peligros por los profundos cambios celulares observados en algunos pacientes, llegando hasta la destrucción total. El interrogante está planteado y confiamos en futuras investigaciones para resolver el problema.

Buena nutrición - Vitaminoterapia-. Supresión de todos los focos sépticos especialmente aquellos localizados en la próstata, vesícula seminales, epididimos y uretra. Buena parte de los casos exigen estudio uretroscópico para estudio de veru-montanum y canales evaculadores.

\section{Resumen:}

a) El factor masculino es de capital importancia y siempre debe estudiarse.

$b$ Existen multitud de causas conocidas de infecundidad masculina y buena parte se pueden corregir.

c) Existen entidades de etiología aún desconocidas o muy pobremente conocidas en las cuales a la luz de los conocimientos modernos, nada es posible utilizar con éxito.

d) Los dos puntos capitales sobre los cuales reposa un buen estudio del hombre infecundo son: El espermograma y la biópsia testitular. Del espermograma los factores más importantes son la motilidad, vitalidad y el el número de formas anormales. Demasiado énfasis e importancia se ha dado a los factores volumen y concentración espermática, es decir, el número de espermatozoides. 